\title{
PEDESTRIAN PRIORITY IN URBAN AREA AND USEFULNESS TOWARDS COMMUNITY
}

\author{
Prof.Sejal S. Bhagat ${ }^{1}$, Er. Manoj L. Patel ${ }^{2}$, Er. Palak S. Shah ${ }^{3}$ \\ ${ }^{1}$ Assistant Professor, Faculty of Civil, Sarvajanik College of Engg. \& Tech, Gujarat, India \\ ${ }^{2} P G$ Student, Civil Engineering, Sarvajanik College of Engg. \& Tech., Gujarat, India \\ ${ }^{3} P G$ Student, Civil Engineering, Sarvajanik College of Engg. \& Tech, Gujarat, India
}

\begin{abstract}
Transportation network has become nerve of any city, the paradox here is that though meant for human travel, these roads hardly provide any quality space for those who are without vehicles (well known as pedestrian). Due to the ambiguous position of nonmotorized travel in an urban transportation system, the transportation conditions for non-motorized travel are getting worse in cities, which illustrate the urgent need for the improvement for same. There is a requirement of combining traffic issues with pedestrian in a comprehensive manner and will make it an important part of road design. Preservation of nature, opportunities for cultural interface, a resource conserving environment with workable public transit and more occasions for walking should be prime objectives of urban planners. For urban development, pedestrian system should be well designed, safe and convenient. The Pedestrian Zone is the primary component of every street in a city. It is not only a zone to ensure smooth, comfortable, conflict free movement of pedestrians and public transport users, but also an area which shapes social interactions, safety and quality of life of people in a city. Pedestrian priority thus becomes a major and a very important phenomenon for urban development which in a way helps quality of life in an urban area. With the increase in population and keeping in view the world pedestrian scenario, this paper will bring some notices to facilities required, mode of travels to be looked upon and other such major issues are discussed.
\end{abstract}

Key Words: Pedestrian Importance, Non motorized transport, Pedestrian Facility and Movement, Urban Scenario

\section{INTRODUCTION}

Almost half of the world's road traffic fatalities occur in developing countries and pedestrian fatality share at the national level is $13 \%$. Whereas metropolitan cities like New Delhi, Mangalore and Kolkata have a pedestrian fatality share greater than $40 \%$, as per CAI-Asia.(Clean Air Initiative) Environmental friendly towns are intended to be largely car free, with pedestrian's environments. In another aspect, $\mathrm{CO}_{2}$ emissions from road transport have increased at $7.75 \%$ per year as per CAI-Asia in 2011. Due to congestion and delay, Liquid fuel consumption rate in transport sector is $28 \%$ of the total petroleum product consumption in India (Planning Commission). So this issue will be needed to be addressed and efficient planning would be required in this area.

[Source: Reference ${ }^{[1,4]}$ ]

Pedestrian characteristics: Pedestrian's characteristics can be divided into various groups such as it can be divided according to physical space required, walking ability, walking speed depends on age, gender, physical condition.

Activities: There are various activities occur in the walkway area like vendors doing business, shopping, parking, construction and other social activities.

MAIN PRINCIPLES:

[A] Mobility - An Obstruction free, safe, comfortable and continuous walking zone must be ensured for pedestrians on all roads of the city.
[B] Ecology: - Usage of Pervious Paving to build Natural Drainage Systems - Reduce Heat Island Effect by increasing paving reflectivity

[C] Safety/Comfort - Provide accessibility ramps and tactile paving for the Handicapped- Continuous and uniform walking area- Trees and high-albedo materials to ensure optimal climatic comfort.

[Source: Reference ${ }^{[3]}$ ]

\subsection{Role of Non Motorized Modes of Travels}

Currently, most urban transportation planning studies in developing countries trends to concentrate on facilities for motorized transport(public \& private). the proliferation of motorization leads to increase traffic congestion, environmental deterioration and traffic accidents. Non motorized transport (NMT) is one of the effective alternates to alleviate negative aspects of motorization. The non motorized mode of travel consist of pedestrian movements, bicycles, cycle rickshaws and animal drawn vehicles. non motorized modes use indigenously available human and animal energy, are non polluting, safe \& user friendly. they involved low cost for operations. this modes are an ideal options for trip length up to $5 \mathrm{~km}$ and are convenient in congested area and for shopping and school trips.

Waking is perhaps the most fundamental mode of transport for short distances and next reliable mode seems to be the bicycles. while pedestrian and bicycle friendly facilities are 
necessary, quality urban environment ensuring safety, proximity and access are also essential to maximize non motorized travel. Extensive intermixing of non motorized and motorized traffic on urban roads leads to traffic congestion increase in journey time and in accidents. the safety of pedestrian and bicyclist deteriorates as motorized increases.

\section{IMPORTANCE OF PEDESTRIAN FACILITIES}

Circulation of pedestrian is of vital importance's to the modern metropolis. the city derives is vitality from the interaction among people at places at business, assembly and recreation. every trip be it by car, bus or train-begins and ends as pedestrian movement. in urban area of developing countries, the pedestrian trips constitutes a significant portion of the total trips. Hence pedestrian traffic management in Indian cities is a major concern deserving serious attention regarding provision of pedestrian facilities. formulation of an effecting process of managing pedestrian traffic as an important element of the total urban transportation system is essential.

\subsection{Planning for Pedestrian Movement}

Development should be arranged to enhance pedestrian experience; easy access to building shelter from the elements; securities and easy access to transit and neighbouring services. priority should be accorded in the design of routes used by school children, senior citizens, physical challenged person and commuters. pedestrian facilities should be continuous along all major streets and highways. this should be direct and interconnect with all the modes of transportation.

It is importance segregates the pedestrian from vehicular traffic to reduced conflicts and accidents. the major facilities for pedestrian on urban roads include sidewalks and pedestrian crossing. the later comprises zebra crossings, under passes and over bridges. until recently very little studies has been directed towards observing pedestrian behaviours and in using such data in the integrated design of the road space with due attention of walking as traffic mode. in consequences the traffic management of pedestrian leaves must be desired.

The characteristics of pedestrian travel should be recognized while designing pedestrian facilities. pedestrian traffic is localized and is highly concentrated in retails and commercials areas. Pedestrian trip purposes vary by location and time of the day. pedestrian tend to keep walking distances as short as possible. if the walking environment is clean and attractive, the walking distance may be increased.

\subsection{Sidewalks}

Sidewalks are provided on most urban arterials, collector street and in commercial and residential areas. however, the quality and the width of sidewalks are often inadequate. it is not uncommon to witness widening of carriageway on the arterials at the expense of sidewalks. such a practice in inadvisable, as the pedestrian tend to spill over to the carriageway causing conflicts with the vehicular traffic. the top surface of the sidewalk should be maintained clean, even and free of dangerous holes, so as to encourage people to use the sidewalk.

The capacity and serviceability of sidewalks in cities are often impaired considerably due to cluttering of service facilities are necessary, their location should be regulated to reduce interface with pedestrian flow. the social considerations of removal of hawkers from the sidewalks defy an equitable solution which would be favourable to the affected poor and at the same time are harmless to the traffic situation. since a significant part of the urban population seems to like the service rendered by the hawkers, it may be desirable for the city authority to consider the possibility of developing of low cost off-street market spaces near crowded areas with relatively low daily/weekly rents so that the number of hawkers on the sidewalks may be reduced. some cities follow the policy of not permitting hawking on footpaths with less than $2.7 \mathrm{~m}$ width. the hawking stall width is then restricted so that a minimum clear width of $1.5 \mathrm{~m}$ is available for pedestrian. the sidewalk should be segregated by a raised kerb of $225 \mathrm{~mm}$ height or be raised from road level. it is observed that low footpaths of 100 to $150 \mathrm{~mm}$ height above road level encourage better usage. provision of guard railing at the kerb has been found effective in preventing pedestrian from straying on to the carriageway. this provision has also been used to channelize pedestrian towards the designated crossings. when railing is provided, the tendency of the hawkers to occupy the sidewalks is discourage by the dominance of the pedestrian, the improvement of sidewalks is perhaps the single most important measure to be attended to by authorities concerned with traffic management in many developing country cities.

\subsection{Pedestrian Crossings}

Designated pedestrian crossings are necessary to ensure safety of pedestrian wishing to cross busy urban roads. the types of pedestrian crossings include: zebra crossing, pedestrian underpass and pedestrian over bridge. while zebra crossings and crossing at signalized intersections or mid block crossing permit time segregation, grade separated crossing such as under pass over bridge facilitate space segregation.

\section{[a] Zebra Crossings}

A zebra crossing is a cheapest device to provide a protected crossing. zebra crossings are to be provided at the intersections and at mid block location, if necessary. the white strips and stop line forming the complete zebra crossing should be provided in the interest of saving lives, though the painting involves additional expenditure. the British highway code requires that the vehicle driver should give priority to pedestrian once he steps on the carriageway on the designated crossing. the compliance of such a stipulation is difficult rely on in developing countries with a large population and low levels of literacy.

The presence of police personnel at these crossings leads to better compliance. provisions of kerb railing for about $50 \mathrm{~m}$ 
on either side of crossings helps to guide the pedestrian traffic on the pedestrian crossings. zebra crossings with pedestrian activated signal control are not very effective in cities in developing countries due to misuse. pedestrian refuges or traffic islands aid pedestrian to cross wide multi lanes roads safely. the width of refuges should be at least

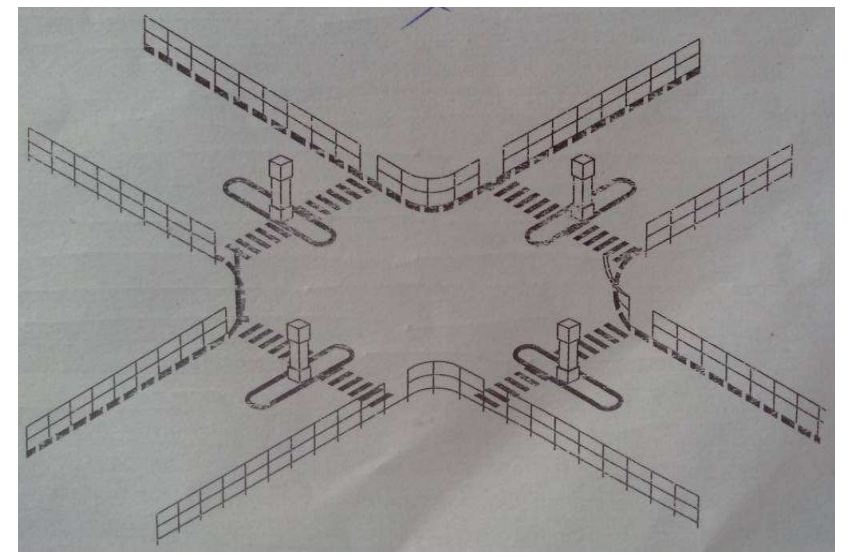

$1.8 \mathrm{~m}$.

Fig -1: Railing \& Pedestrian Crossings at Intersection

\section{[b] Crossings at signalized intersections}

Pedestrian crossing at signalized intersection are found to be very effective however it is necessary to ensure provisions of sufficient green time for the crossing pedestrian, particularly crossing wide roads. the introductions of flashing green signal to indicate the approach of the end of the green time for pedestrian will be useful.

Central refuge \& bollard may also be added as shown in figure to enhance safety.

\section{[C] Pedestrian Underpasses}

Provision of a pedestrian underpass (sometimes referred as subway in India) is an engineering measure towards reduction of accidents. It involves high cost on construction and maintenance. In this system, the vehicular movement is at grade and the pedestrian movement is below in tunnels or underground concourses. Pedestrian underpasses can be constructed by the cut-and-cover method as done in Chennai or by bored tunneling which is prohibitively expensive. The advantage of the underpass include: complete elimination of conflicts between pedestrian and vehicles at point of crossing; built in protection from sun and inclement weather; least disturbance to normal cityscape; and provision of direct linkage to existing underground systems and major activities centers. The disadvantages are: high cost of construction; need for changes in grade and numerous entry points; loss of visual contact with the city surroundings; and potential security problem. If a few well designed shops are established along tunnel part of the underpass, the cost of the underpass can be partially or fully recovered. The entry/exit points of the underpass should be made conspicuous and elegant so as to attract the user. This can be done by attending to lighting, signage and landscaping at the entry/exit. Multi-arm underpasses may be considered at intersection with high volume of pedestrian movements. This will be particularly effective if the pedestrian volume at a signalized intersection requires a cycle time of more than $150 \mathrm{sec}$.

When properly designed and maintained, a pedestrian underpasses can effectively attract users and afford them a protected crossing. On the other hand, an underpass not used by pedestrian due to inappropriate location, inadequate design, unimaginative access treatment, or unsatisfactory perception by the intended user may turn out to be a liability to the community.

A study of the effectiveness of pedestrian underpasses in Chennai has revealed that,

A. a good underpass compliance can be expected only when the traffic on the road is heavy and there is continued police presence.

B. when the width of the carriageway is less then $20 \mathrm{~m}$, it is difficult to expect the pedestrian to use the underpass.

C. pedestrian tends to avoid an underpass with long ramps if the traffic on road is in the form of platoons.

D. the alignment of the underpass tunnel and the access points should be close to the desired lines of the users.

Pedestrian violations at the underpass locations can be reduced by the provision of median railing for about $50 \mathrm{~m}$ on either side of the centerline of the underpass.

\section{[d] Pedestrian over Bridge}

Pedestrian over bridges across roads have generally been unsuccessful, relative to pedestrian underpasses or at-grade crossings. people do not seem to mind walking down first, and by the time they arrive at the other end, are not conscious of the trouble of walking up. in contrast, When they reach an over bridge, people hesitate to climb stairs and look for alternatives. pedestrian over bridges are likely to be successful only across railway tracks and across wide roads with heavy traffic. provision of escalators would encourage the aged and the children to use the over bridges. elevated walkways may be found successful across roads opposite railway stations.

Skywalks are an extension of idea of pedestrian over bridges. it is an elevated walkway dedicated to the pedestrian for accessing facilities. they have been used in many cities in commercial areas to connect different commercial centers. Minneapolis is reported to have the longest network of skywalks connecting 69 blocks.

Mumbai is the first city in India to go in for skywalks on a big way. they mainly aim at provide easy and safe access to busy suburban railway stations by providing skywalks in continuation of foot over bridges in the station. they have planned to provide 50 skywalks in the metropolitan area at a cost of about Rs.600crores. they will connect railway stations of high concentration and commercial points to destinations having heavy pedestrian flow some of them have already been completed. other cities in India are also planning for skywalks at important locations. 


\section{PEDESTRIAN MALLS AND PEOPLE MOVER SYSTEMS}

As traffic grows to meet the capacity of the road space, the quality of life in the CBD tends to suffer from the adverse effects of motor traffic; smoke, noise, visual intrusion and lack of safety. This is particularly evident in shopping activities. Current trend is to declare certain areas in the CBD as pedestrian malls (also known as pedestrian precincts) as part of redevelopment, e.g., Coventry city centre and stevenage town centre in the UK, and certain areas in the historic part of Munich, Germany. A policy of traffic restraints is followed to permit servicing of the shops during the night hours. Exclusion of motorized vehicular traffic in a large part of the city centre enhances the environmental quality and the facilitation of comfortable shopping leads to commercial benefits. For success of pedestrianisation, good public transport facilities, especially rail transit and convenient parking for private vehicles at the periphery of pedestrian malls are essential.

People mover systems are those specially meant for movement of car users from the fringe parking lots to the activity centers. there are many variants to these systems, including moving belts, minibuses, electric trains like those in world fairs, and monorail systems. An integration of people movers, shopping areas, parking garages can be innovatively managed so as to revitalize the CBD area, at the same time providing for various modes of traffic.

\section{PEDESTRIAN DESIGN GUIDELINES}

The Governing Body of Unified Traffic and Transportation Infrastructure (Plg. \& Engg.) Centre (UTTIPEC) under the Chairmanship of Sh. Tejendra Khanna, Hon'ble Lt. Governor has approved the "Pedestrian Design Guidelines" on 20.11.09 as per the recommendation of the Working Group for immediate implementation, enforcement and uniform adoption by all the road owning agencies.

Working Group had made deliberations in its various meetings with the members, experts and resource persons in the field of Urban Planning and Design, who have contributed towards formation and finalization of this document. The document contains graphics, sketches, photographs on each aspect apart from brief write ups, to make it more user-friendly.

$\Rightarrow$ Streets are valuable public spaces as well as movement corridors.

$\Rightarrow$ Design of Streets is a function of the Street Hierarchy and Adjacent Land uses.

$\Rightarrow$ Certain Street Design Components are nonnegotiable.

$\Rightarrow$ These components and additional guidelines for world class streets - have been outlined in this document.

[Source: Reference ${ }^{[3]}$ ]

\subsection{Increased Pedestrian Design consideration}

$\Rightarrow$ Increase in comfort for current walking population.
$\Rightarrow$ Comfortable last mile connectivity from MRTS Stations - therefore increased ridership of buses and Metro.

$\Rightarrow$ Reduced dependency on the car, if shorter trips can be made comfortably by foot.

$\Rightarrow$ More exercise, so better health for people walking.

$\Rightarrow$ Prioritization of public transport and non-motorized private modes in street design

$\Rightarrow$ Reduced car use leading to reduced congestion and pollution.

$\Rightarrow$ More equity in the provision of comfortable public spaces and amenities to all sections of society.

[Source: Reference ${ }^{[2]}$ ]

\subsection{Essential Components of all streets}
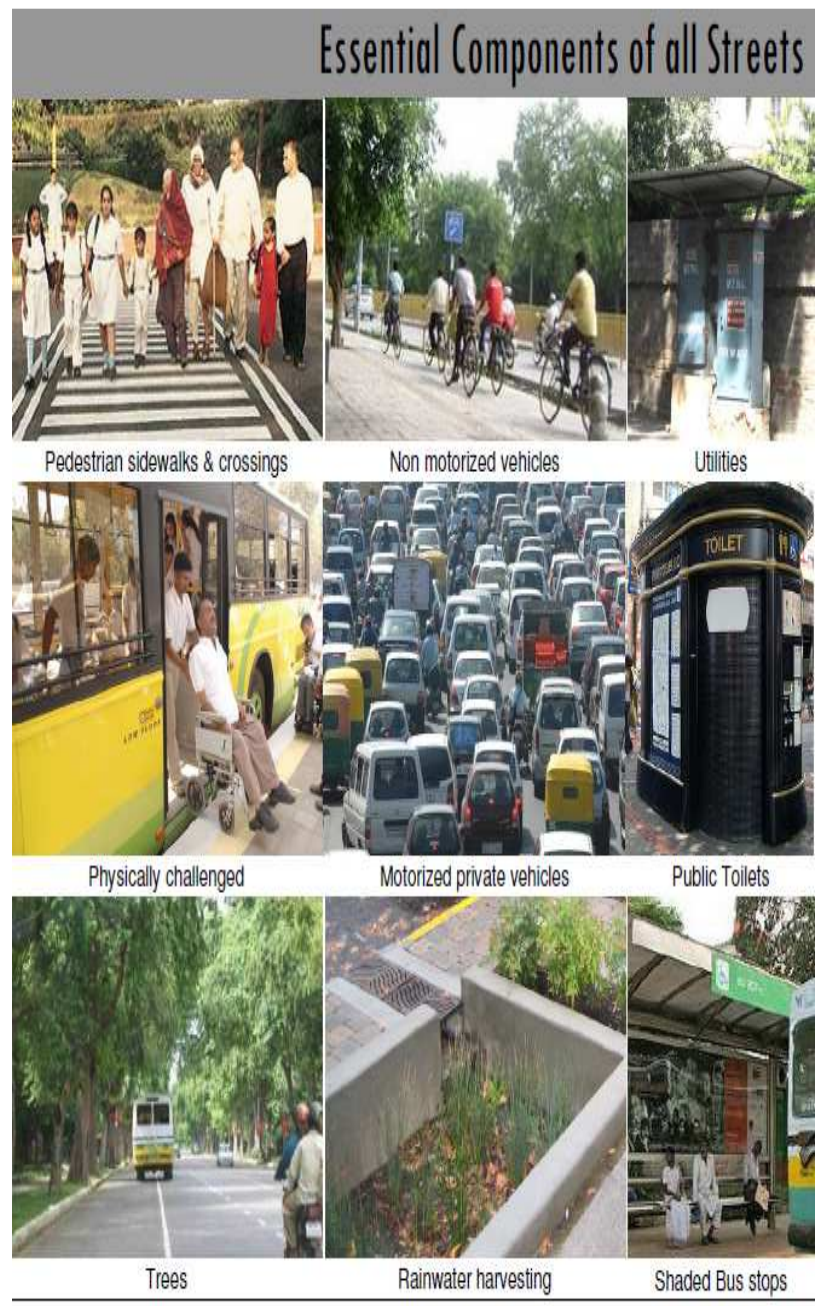

Fig -2: Essential Components of all Streets

There should be essential components of streets includes Pedestrian sidewalks and crossings, Non motorized vehicles, utilities, facility concern to physically challenged, Private vehicles, Public toilets, Trees, Rain water harvesting, well facilitate bus stops, etc. Each and everyone components equally weighted and take care to get better pedestrian responses in feedback. One single component will also connected to single or more community in direct or indirect way. 


\section{Dead Width or Frontage Zone}

Dead width well known as space that are used for market activities like vendors, Newspaper seller, etc. So, planning regarding this must consider space for dead width and extra more space needed for pedestrian easy movements.

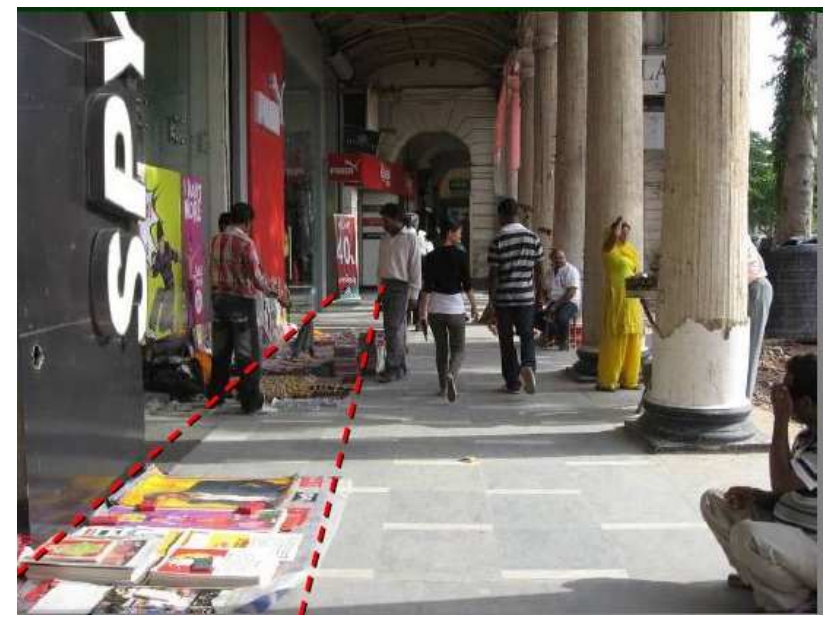

Fig -3: Dead Width

\section{CONCLUSIONS}

As per the above discussions we can say that pedestrian must be considered as one of the most important and an inevitable part of urban planning element. It will not only be useful to some percentage of overall population but rather would be helpful to everyone in need and who would not want to take the risk of accidents including all and each single possibility. Pedestrian facility with properly design directly encouraging community towards safer direction view point for happy life. Pedestrian facility which is less or not available to enough people that increases damage of lives. "Nothing is precious than life" sentence is suitable to this type of situation. Pedestrian facility will definitely be used when provided due to tremendous requirement. Pedestrian facility provision with a proper management will give unbelievable positive growth of community. Unacceptably high accident rates gives warning to all and that same discourage smooth vehicular traffic movement. Dedicated lanes for HOVs(high occupancy vehicles) and carpool during peak hours is also important to solve traffic issues.

Bicycles, Rickshaws and other Non-Motorized transport are essential and the most eco-friendly feeder services. They are also indispensible for short \& medium length trips for shopping, daily needs, school, etc. Providing safe and segregated NMT lanes on all Arterial and Collector Streets would encourage their use and reduce the dependency of people on the private car. Mixing of all type of modes slow down activities of everyone and creates chaos.

\section{ACKNOWLEDGEMENT}

There must be thanking words for who motivate to write this paper and give idea about clear concept through word for the world. Guidance and Comments on a draft of this paper were received from Prof. Sejal Bhagat, Assistant Professor, Civil Engineering Department, SECT. The author is grateful to her. Weaknesses and mistakes remain the author's responsibility. This paper should be seen as a work in progress, and will evolve with further feedback and experiences for better future work. Therefore, Comments are most welcome.

\section{REFERENCES}

[1]. Asst. Prof. Rikta Desai \& Asst. Prof Alpa Pandya faculty of Architecture(SCET), Safe Pedestrian Culture on Urban Road: a Need of Time, 59 th National Town \& Country Planners Congress Conference

[2]. Dr. Johnson Victor, S. Ponnuswamy, Urban transportation, Planning, Operation \& Management, The McgrowHill Companies, 2012, pg. 211-217.

[3]. Pedestrian Design Guidelines (C) UTTIPEC, Delhi Development Authority, New Delhi, November 2009

[4]. Pritikana Das, Prof. M. Parida, Prof. V.K. Katiyar(CTRANS), IIT Roorkee, Strategies for Improving Pedestrian Infrastructure in Urban Areas in India, 61st National Town \& Country Planners Congress Conference, Ahmedabad(2013) P.G.345 - 354

\section{BIOGRAPHIES}

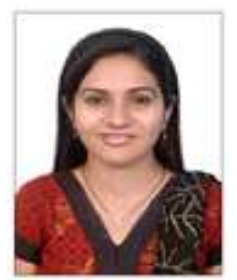

Prof. Sejal S. Bhagat

Assistant Professor

M.Tech, (Planning)

Sarvajanik College Of Engineering

and Technology, Surat.

Tel.:+919099972849

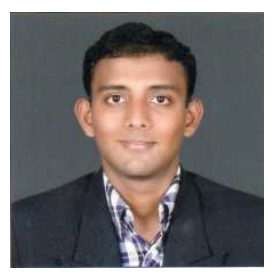

Er. Manoj L. Patel (PG Student)

Master of Civil Engineering

Course: Town and Country

Planning, Sarvajanik College Of

Engineering and Technology,

Surat.

Tel.:+919427478704

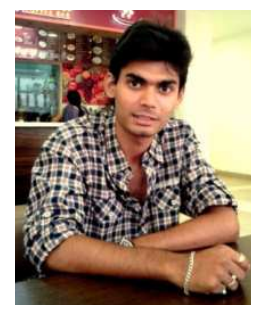

Er. Palak S. Shah (PG Student)

Master of Civil Engineering

Course: Town and Country

Planning, Sarvajanik College Of

Engineering and Technology,

Surat.

Tel.:+919033953607 